\title{
Exploring Influences of Teachers' Social Behaviors on Students' Social Skills in Physical Education Classes: An Example with Chinese College Freshmen
}

\author{
Ningning Sheng1*, Jiandong Ding², Yoshio Sugiyama² \\ ${ }^{1}$ Department of Physical Education, Dalian Ocean University, Dalian, China \\ ${ }^{2}$ Faculty of Human Environment, Kyushu University, Fukuoka, Japan \\ Email: *yyshengningning@163.com
}

How to cite this paper: Sheng, N. N., Ding, J. D., \& Sugiyama, Y. (2018). Exploring Influences of Teachers' Social Behaviors on Students' Social Skills in Physical Education Classes: An Example with Chinese College Freshmen. Advances in Physical Education, $8,35-45$.

https://doi.org/10.4236/ape.2018.81005

Received: January 1, 2018

Accepted: February 8, 2018

Published: February 11, 2018

Copyright $\odot 2018$ by authors and Scientific Research Publishing Inc. This work is licensed under the Creative Commons Attribution International License (CC BY 4.0).

http://creativecommons.org/licenses/by/4.0/

c) (i) Open Access

\begin{abstract}
This study explored the influences of physical education (PE) teachers' social behaviors on students' social skills in PE classes through investigating a sample of Chinese college freshmen. First, we developed a scale to determine teachers' social behaviors enacted while teaching PE. Items of the scale were selected from the pre-version of Teacher's Social Skills Self-report Scale and changed from a teacher self-report to a student-evaluation style based on the specificity of PE context and the native culture of China. Students $(n=366$, 194 male, 172 female, mean age $=18.6$ years) from two universities in China completed a survey using a questionnaire contains the selected items. Through performing factor and reliability analyses, the scale was demonstrated to have acceptable internal consistency reliability and good content validity for measuring college students' evaluations of their PE teachers' social behaviors in PE classes toward two sub-domains named expressivity and control. Then, the developed scale and the 11 Item of Social Skills Inventory were administered to a sample of freshmen $(n=302,157$ male, 145 female, mean age $=17.7$ years) to examine their high school PE teachers' social behaviors while teaching PE and their social skills in current PE classes, respectively. Correlation and regression analyses were performed to determine the relationships between the two variables. Results of correlation analyses indicated that teachers' social behaviors had a significant correlation with both male and female students' nonverbal skills $(r=0.221, p<0.01 ; r=0.147, p<0.05)$. Results of multiple regression analysis revealed that teachers' control behaviors had a positive and significant influence on both male and female students' nonverbal skills ( $\beta=0.373, p<0.05 ; \beta=0.315, p<0.05)$. At the end, implications of the findings were discussed.
\end{abstract}




\section{Keywords}

Influences, Teacher, Social Behaviors, College Freshmen, Verbal Skills, Nonverbal Skills, Physical Education Classes

\section{Introduction}

Recent years in China, studies had found a phenomenon of over-using smart phone among college students and corresponding problems of social skills deficiencies in those students (e.g., Tong, 2013; Wang, 2012; Wang, 2014; Xia, 2013). Social skills can help students to make choices to strengthen their interpersonal relationships and contribute to making a positive and safe school environment, and also can help them to develop resilience to deal with stressful events or crises in the future (NMHEC, 2002). Therefore, researchers and educators in China are responsible to develop strategies to teach college students' social skills. PE can provide students with a numerous opportunities to interact with others in classes. It is a powerful mechanism and one of the best venues in school to promote students' social skills (Eldar et al., 2006; González, Regalado, \& Guerrero, 2010). Studies had been conducted for many years on developing and implementing models and programs in PE to promote students' social skills in western and other countries (Metzler, 2011). However, studies on exploring the mechanism of how students' social skills can be developed through learning in PE are still limited, especially in China. To develop and implement strategies efficiently and effectively in PE, it is necessary to study in this field. Students' social skills may be developed by the influences of certain variable factors. Discovering these factors can help researchers and educators understand the mechanism and create a valuable learning environment to develop students' social skills. In school, teachers' behaviors affect students' learning and achievement (Engstrom, 2000). Teachers are powerful socializing agents who have the strong influences on students' beliefs and actions (Smokowski, Reynolds, \& Bezruczko, 1999; Winfield, 1991). PE teachers' actions in making syllabi, teaching skills, implementing strategies, and managing classes can largely determine the levels of students' physical and psychosocial development. Therefore, PE teachers may be an important factor influencing students' social skill in classes. The purpose of this study was to explore the influences of PE teachers' social behaviors on students' social skills in PE classes through developing a student-evaluation scale that can be used to assess teachers' social behaviors in PE classes.

\section{Methods}

\subsection{Instruments}

\subsubsection{Items Selected from the Pre-Version of Teachers' Social Skills Self-Report Scale (TSSSS)}

Aikawa in 2011 selected and revised 53 items from the Social Skills Self-Rating 
Scale for Adults (Aikawa \& Fujita, 2005) to develop the TSSSS and finally employed 46 items for the developed version. The TSSSS assesses a teacher's basic social behaviors interacted with students across six subscales: starting interactions, solving conflicts, considerations, emotion control, decoding nonverbal behaviors, and claiming. Each item must be answered on a four-point Likert scale ranging from "not at all like me" to "exactly like me." There is an identical score corresponding to each item so that the scores of the scale range from 46 to 184. The scale has demonstrated content validity and an internal consistency reliability coefficient of 0.938 with a sample of Japanese teachers (Aikawa, 2011). In this study, we selected 15 items from the pre-version of TSSSS and modified them to develop a scale that can be used to examine PE teachers' social behaviors in classes. First, the original 53 items were translated from the Japanese to a Chinese version. The translation was conducted by three Chinese master course students who had been in Japanese language major and had passed the Japanese Language Proficiency Test of level 1. We then selected and modified items by fully considering the specificity of PE context and native Chinese culture, and transformed the wording of the selected items from a teacher self-report to a student-evaluation style. Of the selected 15 items, 14 items had been employed in the developed TSSSS but the rest one (item 14) had been not (Table 1).

Table 1. Items selected from the pre-version of the TSSSS.

\begin{tabular}{|c|c|c|c|}
\hline $\begin{array}{l}\text { Number in } \\
\text { this study }\end{array}$ & Items & \multicolumn{2}{|c|}{$\begin{array}{l}\text { Original item number and } \\
\text { subscale domain }\end{array}$} \\
\hline 1 & PE teacher got along well with each student in the class. & 6 & \multirow{7}{*}{ Starting interactions } \\
\hline 2 & PE teacher had multiple expressions when teaching in the class. & 9 & \\
\hline 3 & PE teacher is good at communicating with students in the class. & 14 & \\
\hline 4 & PE teacher can join students' conversation easily in the class. & 19 & \\
\hline 5 & PE teacher often uses gestures and postures when talking in the class. & 22 & \\
\hline 6 & PE teacher always greet students pleasantly in the class. & 23 & \\
\hline 10 & PE teacher is good at starting a conversation with students in the class. & 36 & \\
\hline 9 & PE teacher can deal with problems well in the class. & 33 & \multirow{2}{*}{ Solving conflicts } \\
\hline 11 & PE teacher can calm students down easily when they are angry in the class. & 38 & \\
\hline 7 & PE teacher is always serious when listening to students in the class. & 26 & \multirow{4}{*}{ Considerations } \\
\hline 12 & PE teacher respects students in the class. & 42 & \\
\hline 13 & PE teacher can give good responds to students' opinions in the class. & 47 & \\
\hline 15 & $\begin{array}{l}\text { PE teacher is considerate of students' emotions and feelings when talking with } \\
\text { them in the class. }\end{array}$ & 52 & \\
\hline 8 & PE teacher can control his/her emotion well when teaching in the class. & 30 & Emotion control \\
\hline 14 & PE teacher often praises or encourages students in the class. & 51 & \\
\hline
\end{tabular}




\subsubsection{Item of Social Skills Inventory (11-SSI)}

The Social Skills Inventory (SSI) (Riggio, 1986, 1989) is a standardized and representative measurement developed to assess certain key dimensions of adults' social skills in daily life. The scale examines social skills in six subscales: emotional expressivity, emotional control, emotional sensitivity, social expressivity, social control, and social sensitivity. Emotional expressivity, emotional control, and emotional sensitivity measure people's nonverbal skills; while social expressivity, social control, and social sensitivity are subscales that measure people's verbal skills. As students' social behaviors can be learned in one domain (e.g., PE classes) and transferred or generalized to other fields (e.g., family, school, \& community) (Maureen, Nicole, \& Lindsay, 2014), students' social skills acquire in a PE setting may be different from those they use in their daily lives (Sugiyama et al., 2010). By considering the differences of students' social skills between in and out of the PE classes, Ding and Sugiyama (2016) selected 11 items from Riggio's SSI and revised them according to the context of PE and social culture of China, to develop the 11-SSI to examine Chinese college students' social skills in PE classes. The 11-SSI assesses students' basic communication skills in PE classes across two subscales: verbal skills (five items) and nonverbal skills (six items). For example, the items "I feel very uncomfortable when being criticized" and "It is difficult for me to speak when facing all class members" assess students' social sensitivity and social expressivity, which reflect their verbal skills in PE classes; while the items "When I feel sad or depressed, others can hardly detect my feelings" and "I am good at express myself by eyes" determine students' emotional control and emotional expressivity, which are aspects of their nonverbal skills in PE classes. Each item must be answered on a five-point Likert scale including two negative and three positive agreement responses ranging from "not at all like me" to "exactly like me." Each item is corresponded with an identical score so that the subscales are scored ranging from 5 to 30 . The scale has demonstrated an internal consistency reliability coefficient of 0.92 and content validity with a sample of Chinese college students (Ding \& Sugiyama, 2016).

\subsection{Participants and Procedures}

We carried out two surveys separately in June, 2014 and October, 2014. College students from two universities at two cities (i.e., Dalian \& Sanya) in China were investigated. In the first survey, a measurement contains 15 items selected and revised from the pre-version of TSSSS was administered to a sample of $366 \mathrm{stu}$ dents (mean age $=18.6$ years) that included 194 students at the university in Dalian and 172 students at the university in Sanya. Students at the university in Dalian were 100 freshmen (55 male, 45 female) and 94 sophomores (50 male, 44 female); students at the university in Sanyawere 89 freshmen ( 46 male, $43 \mathrm{fe}$ male) and 83 sophomores (43 male, 40 female). Forty freshmen (23 male, 17 female) at the university in Dalian retook the questionnaire two weeks after the initial administration. The data of the first survey was used to develop a student-evaluation scale to assess PE teachers' social behaviors in classes. In the 
second survey, the developed scale and the 11-SSI were administered to a sample of 302 freshmen (mean age $=17.7$ years) who had been studying in college for only one month. The sample included 155 students ( 81 male, 74 female) at the university in Dalian and 147 students (76 male, 71 female) at the university in Sanya. The data of the second survey was used to assess the influences of teachers' social behaviors on students' social skills in PE classes.

The ethics application for this study was approved by the first author's university. In the first survey, we phoned the chairs of PE department of the two universities to explain the investigations and acquire approvals to perform them. After we had received the approvals and agreements of assistance from the two chairs, we sent questionnaires to the two PE departments by post. The two chairs then called for PE teachers to administer the questionnaires. Each administration was conducted before a lesson in a quiet place (e.g., a play-ground far from other class groups or a classroom) without distractions. The questionnaires were collected and returned by post after administration. After two month, we carried out the second survey by the same means as of the first survey.

\subsection{Data Analysis}

We performed exploratory factor analysis to examine factor components of the new scale. Reliability of the scales was verified by calculating Cronbach's a coefficient and the test-retest correlation $r$. We used confirmatory factor analysis to determine the validity of the new scale. Correlation analyses were performed to determine whether there are relationships between teachers' social behaviors and students' social skills in PE classes. Multiple regression analyses were conducted to examine the influences of teachers' social behavior on students' social skills in PE classes. Data were analyzed using SPSS 22.0 and Amos 22.0 for Windows.

\section{Results}

\subsection{Factor Components of the New Scale}

In order to determine whether the items of students' views assessed distinct aspects of PE teachers' social behaviors in classes, we performed an exploratory factor analysis by using the principal components method with varimax rotation, on the sample $(n=366)$ of the first survey. Bartlett's test of sphericity (1122.840) and the Kaiser-Mayer-Olkin (KMO) statistic (0.922) suggested that it was necessary and feasible to perform factor analysis. First, we derived two factors by setting the eigenvalues higher than 1.0. With regards to the eigenvalues, the eigenvalue of factor 1 was 4.673 and that of factor 2 was 3.829. The curve on the scree plot (not shown here) became smooth after the second factor. Then we performed the factor analysis again by extracting the number of factors with 2 , and suppressing the absolute values of factor loadings less than 0.3 . The result revealed that the factor loadings were all greater than 0.4 . Thus, we employed all items and according to the distributions of the items in the TSSSS and in this study, we named the two factors "control" (eight items) and "expressivity" (seven 
items), respectively. Finally, the scale called Student-evaluation Scale of Teachers' Social Behaviors (SSTSB) was developed (Table 2).

\subsection{Reliability and Validity of the SSTSB}

Cronbach's $\alpha$ coefficient is reliability index of internal consistency. In this study, we calculated a coefficient to assess the reliability of the SSTSB. The coefficient of the total scale was 0.924 and those of the subscales were 0.871 (control) and 0.880 (expressivity). In addition, we conducted a correlation analysis for the scores of two-week test-retest. The correlation coefficient $r$ for the total scale was $0.891(p<0.01)$ and those for the subscales were $0.875(p<0.01)$ (control) and 0.909 ( $p<0.01)$ (expressivity). Thus, the results (Table 3 ) verified that the reliability of the SSTSB was acceptable.

To assess the validity of the factor component of the SSTSB in evaluating students' views of PE teachers' social behaviors in classes, we performed a confirmatory factor analysis on the sample $(n=366)$ of the first survey (Figure 1$)$. The

Table 2. Result of exploratory factor analysis $(n=366)$.

\begin{tabular}{|c|c|c|c|c|}
\hline \multirow[b]{2}{*}{ Items } & \multirow[b]{2}{*}{ Mean } & \multirow[b]{2}{*}{$\mathrm{SD}$} & \multicolumn{2}{|c|}{ Factor loadings } \\
\hline & & & $\begin{array}{c}\text { Factor } 1 \\
\text { (Control) }\end{array}$ & $\begin{array}{c}\text { Factor } 2 \\
\text { (Expressivity) }\end{array}$ \\
\hline 1 & 2.962 & 0.813 & 0.491 & \\
\hline 8 & 2.977 & 0.842 & 0.693 & \\
\hline 9 & 3.058 & 0.816 & 0.617 & \\
\hline 11 & 2.741 & 0.849 & 0.608 & \\
\hline 12 & 3.153 & 0.800 & 0.603 & \\
\hline 13 & 2.916 & 0.818 & 0.781 & \\
\hline 14 & 2.854 & 0.876 & 0.722 & \\
\hline 15 & 2.891 & 0.916 & 0.769 & \\
\hline 2 & 3.049 & 0.873 & & 0.805 \\
\hline 3 & 2.962 & 0.837 & & 0.671 \\
\hline 4 & 2.913 & 0.880 & & 0.649 \\
\hline 5 & 3.107 & 0.843 & & 0.792 \\
\hline 6 & 2.742 & 0.931 & & 0.621 \\
\hline 7 & 2.786 & 0.872 & & 0.531 \\
\hline 10 & 2.853 & 0.918 & & 0.567 \\
\hline Eigenvalues & & & 4.673 & 3.829 \\
\hline Variance explained (\%) & & & 31.156 & 25.528 \\
\hline
\end{tabular}

Table 3. Coefficients of internal consistency a and test-retest correlation $r$ for the SSTSB.

\begin{tabular}{ccc}
\hline & Cronbach's $\alpha$ & Test-retest $r$ \\
\hline Control & 0.871 & $0.875^{* *}$ \\
Expressivity & 0.880 & $0.909^{\star *}$ \\
Total social behaviors & 0.924 & $0.891^{\star *}$ \\
\hline
\end{tabular}




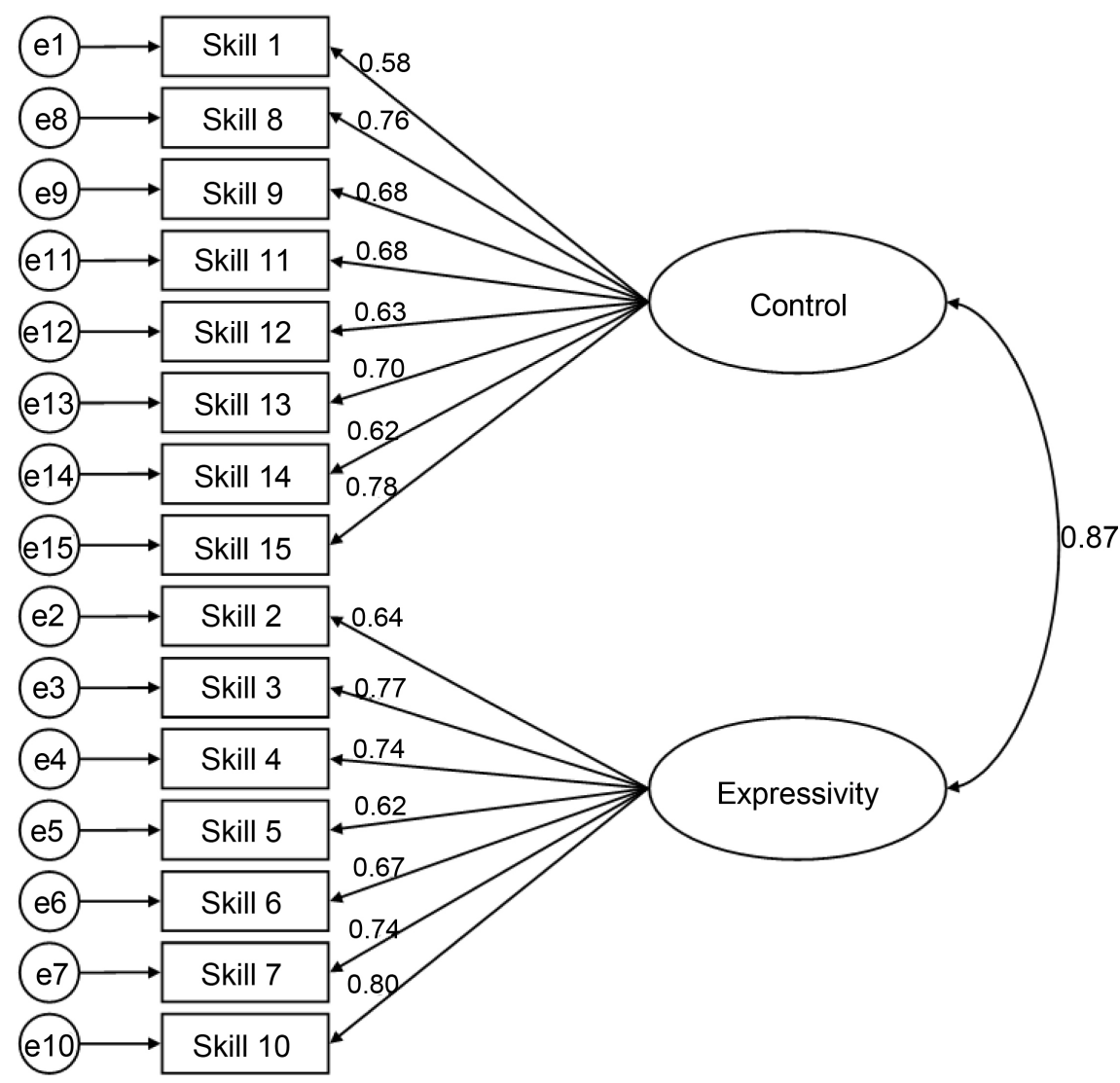

Figure 1. Result of confirmatory factor analysis $(n=366)$.

goodness of fit index (GFI) was 0.926. The adjusted goodness of fit index (AGFI) was 0.933 . The comparative fit index (CFI) was 0.945 . The root mean square error of approximation (RMSEA) was 0.047 . The results suggested that the hypothesized two-factor model that was developed based on the results of exploratory factor analysis fit the data reasonably well.

\subsection{Results of Correlation Analyses}

In order to determine whether there were relationships between PE teachers' social behaviors and students' social skills in the classes, we performed correlation analyses separately on male samples $(n=157)$ and female samples $(n=145)$ of the second survey. Results (Table 4 ) showed that teachers' social behaviors had a significant correlation with nonverbal skills in both male $(r=0.221, p<0.01)$ and female students $(r=0.147, p<0.05)$. However, no significant correlation was found between teacher' social behaviors and verbal skills either in male or female students.

\subsection{Influences of Teachers' Social Behaviors on Students' Social Skills in PE Classes}

In order to determine whether teachers' social behaviors have an influence on students' social skills in PE classes, we performed multiple regression analyses 
separately on male samples $(n=157)$ and female samples $(n=145)$ of the second survey. First, collinearity diagnostics indicated that the collinearity for variables of teachers' social skills in each sample was weak (VIF $=1.235-1.731)$. Then, two aspects of teachers' social behaviors (i.e., control \& expressivity) were entered to regress on each sample's verbal and nonverbal skills. Results (Table 5) showed that the $R^{2}$ of the regression equation in which teachers' social behaviors were regressed on nonverbal skills reached the significant level in both male $\left(R^{2}=\right.$ $0.218, p<0.01)$ and female students $\left(R^{2}=0.107, p<0.05\right)$. It indicated that teachers' social behaviors had a strong influence on nonverbal skills in all students. Of the two aspects of teachers' social behaviors, control domain was found to have a positive and significant influence on nonverbal skills in both male $(\beta=0.373, t=2.179, p<0.05)$ and female students $(\beta=0.315, t=2.056, p<$ $0.05)$. However, expressivity domain was found to have no significant influence on verbal skills either in male or female students.

\section{Discussion}

The current study assessed the influences of high school PE teachers' social behaviors on students' social skills in PE classes through developing the SSTSB. The SSTSB was demonstrated to have acceptable reliabilities and a good content validity in measuring college students' evaluations of their high school PE teachers' social behaviors in classes toward two sub-domains that are control

Table 4. Teachers' total social behaviors in relation to male and female students' verbal and nonverbal skills.

\begin{tabular}{ccc}
\hline & \multicolumn{2}{c}{ Teachers' total social behaviors } \\
\cline { 2 - 3 } & Male $(n=157)$ & Female $(n=145)$ \\
\hline Verbal skills & 0.031 & -0.003 \\
Nonverbal skills & $0.221^{* *}$ & $0.147^{*}$ \\
\hline
\end{tabular}

Note: ${ }^{*} p<0.05,{ }^{* *} p<0.01$.

Table 5. Regression models of teachers' social behaviors in relation to male and female students' verbal and nonverbal skills.

\begin{tabular}{ccccccccc}
\hline & \multicolumn{3}{c}{ Verbal skills $^{\mathrm{a}}$} & \multicolumn{5}{c}{ Nonverbal skills $^{\mathrm{a}}$} \\
\cline { 2 - 8 } & $\beta$ & $S E$ & $t$ & $R^{2}$ & $\beta$ & $S E$ & $t$ & $R^{2}$ \\
\hline Male $(n=157)$ & & & & & & & & \\
Control & 0.246 & 0.194 & 1.281 & & 0.373 & 0.180 & $2.179^{*}$ & \\
Expressivity & -0.238 & 0.231 & -1.240 & & 0.146 & 0.207 & 1.337 & \\
& & & & 0.042 & & & & $0.218^{* *}$ \\
Female $(n=145)$ & & & & & & & & \\
Control & 0.033 & 0.111 & 0.188 & & 0.315 & 0.123 & $2.056^{*}$ & \\
Expressivity & -0.039 & 0.115 & -0.223 & & 0.036 & 0.159 & 0.372 & \\
& & & & 0.001 & & & & $0.107^{*}$ \\
\hline
\end{tabular}

Note: a Dependent variable. ${ }^{*} p<0.05,{ }^{* *} p<0.01$. 
and expressivity domain. Through conducting correlation analyses, we found significant connections between teachers' social behaviors and students' social skills in PE classes, which provided the basis to explore the effects of teachers' social behaviors on students' social skills in PE classes. In this study, for the first-year students who have been studying in college for only one month, their high school PE teachers' social behaviors in control domain enacted during the past three years were found to have a positive influence on their nonverbal skills in PE classes. People's control behaviors reflect their abilities in regulating communications. A PE teacher's social behaviors in regulating the communications occurred between him/her and students, or between students, can create a harmonious class context to have students receive positive sport experiences through participating physical activities. Students' social skills can be developed by the influences of the positive sport experiences involved enjoyment and self-disclosure in PE classes (Ding \& Sugiyama, 2017). A teacher's communication behaviors could influence students' enjoyment (Cai, 1998; Cecchini et al., 2001; Chalmers, 1992; Hashim, Grove, \& Whipp, 2008) and willingness of self-disclosure (Anita et al., 1977) in PE classes. A teacher's behavior interacting with students such as recognizing their efforts, encouraging them, and showing patience relate to students' positive experiences of PE (Thompson, Mandigo, \& Halas 1998). Therefore, PE teachers are an important factor influencing students' social skills in PE classes. They should not only realize their obligations and work functions related to students' social development, but also be aware and carefully perform their social behaviors in the classes. For example, PE teacher should be helpful in the classes. Students who feel supported by teachers and friends are more likely to view the curriculum as socially appropriate and value physical activity highly; PE teachers who created perceptions of autonomy support for students would positively affect their attitudes and intentions to carry out the desired behaviors (Hagger et al., 2009). PE teachers' social behaviors are performed in various verbal and nonverbal ways in classes. The behaviors can affect students' valuation about the curriculum and physical activity (Daigle, 2003). They should carefully organize them to make positive influence on students' social skill. For example, they should always dress professionally in classes as the appearances express their attitudes and may affect students' copying behaviors in nonverbal domain.

\section{References}

Aikawa, A., \& Fujita, M. (2005). An Attempt to Construct a Social Skills Self-Rating Scale for Adults. Bulletin of Tokyo Gakugei University, Educational Sciences, 56, 87-93.

Aikawa, A. (2011). Development of a Self-Report Scale to Measure Teacher's Social Skills. Bulletin of Tokyo Gakugei University, Educational Sciences, 62, 133-148.

Anita, E. W., Karen, S. G., \& Mark, J. N. (1977). The Impact of Teacher Behavior, Teacher Sex, and Student Sex upon Student Self-Disclosure. Contemporary Educational Psychology, 2, 124-132. https://doi.org/10.1016/0361-476X(77)90015-7

Cai, S. X. (1998). Student Enjoyment of Physical Education Class in Three Teaching Style Environments. Education, 118, 412-421. 
Cecchini, J. A., Gonzalez, C., Carmona, A. M., Arruza, J., Escarti, A., \& Balague, G. (2001). The Influence of Physical Education Teacher on Intrinsic Motivation, Self-Confidence, Anxiety, and Pre- and Post-Competition Mood States. European Journal of Sport Science, 1, 1-11. https://doi.org/10.1080/17461390100071407

Chalmers, S. (1992). The Influence of Teachers on Young Women's Experiences of Physical Education. New Zealand Journal of Health, Physical Education and Recreation, 25, 3-6.

Daigle, K. G. (2003). Gender Differences in Participation of Physical Activities: A Comprehensive Model Approach. Unpublished Doctoral Dissertation, Baton Rouge, LA: Louisiana State University.

Ding, J., \& Sugiyama, Y. (2016). Development of a Scale to Assess Chinese College Students' Social Skills in Physical Education Classes. Journal of Heal Science, 38, 11-19.

Ding, J., \& Sugiyama, Y. (2017). Exploring Influences of Sport Experiences on Social Skills in Physical Education Classes in College Students. Advances in Physical Education, 7, 248-259. https://doi.org/10.4236/ape.2017.73020

Eldar, E., Morris, D., DaCosta, R., \& Wolf, T. (2006). “Are You Square?”: A Game for Developing Self-Control and Social Skills. Strategies, 19, 17-21. https://doi.org/10.1080/08924562.2006.10591200

Engstrom, D. (2000). Correlations between Teacher Behaviors and Student Evaluations in High School Physical Education. Physical Educator, 57, 193-201.

González, M. C., Regalado, M. M., \& Guerrero, J. T. (2010). Teaching and Learning Social Values: Experience of Resolution of Conflicts in the Classroom of Physical Education across the Learning of Social Skills. Journal of Human Sport and Exercise, 5, 497-506. https://doi.org/10.4100/jhse.2010.53.20

Hagger, M., Chatzisarantis, N. L. D., Hein, V., Soos, I., Karsai, I., Linhunen, T., \& Leemans, S. (2009). Teacher, Peer and Parent Autonomy Support in Physical Education and Leisure-Time Physical Activity: A Trans-Contextual Model of Motivation in Four Nations. Psychology and Health, 24, 689-711. https://doi.org/10.1080/08870440801956192

Hashim, H. A., Grove, J. R., \& Whipp, P. (2008). Testing a Model of Physical Education Enjoyment and Physical Activity among High School Students. Journal of Research in Health, Physical Education, Recreation, Sport and Dance, 3, 95-99.

Maureen, R. W., Nicole, D. B., \& Lindsay, E. K. (2014). Assessing Impact of Physical Activity-Based Youth Development Programs: Validation of the Life Skills Transfer Survey (LSTS). Research Quarterly for Exercise and Sport, 85, 263-278.

https://doi.org/10.1080/02701367.2014.931558

Metzler, M. W. (2011). Instructional Models for Physical Education (3rd ed.). Scottsdale, AZ: Holcomb Hathaway.

National Mental Health and Education Center (NMHEC) (2002). Social Skills: Promoting Positive Behavior, Academic Success and School Safety. http://www.naspcenter.org/fastsheets/socialskills_fs.html

Riggio, R. E. (1986). Assessment of Basic Social Skills. Journal of Personality and Social Psychology, 51, 649-660. https://doi.org/10.1037/0022-3514.51.3.649

Riggio, R. E. (1989). Manual of the Social Skills Inventory. Palo Alto, CA: Consulting Psychologists Press.

Smokowski, P. R., Reynolds, A. J., \& Bezruczko, N. (1999). Resilience and Protective Factors in Adolescence: An Autobiographical Perspective from Disadvantaged Youth. Journal of School Psychology, 37, 425-448.

https://doi.org/10.1016/S0022-4405(99)00028-X 
Sugiyama, Y., Shibukura, T., Nishida, T., Ito, T., Sasaki, B., \& Isogai, H. (2010). Development of Scales for Psychosocial Skills in Physical Education and Life Skills. Journal of Health Science, 32, 77-84.

Thompson, L., Mandigo, J., \& Halas, J. (1998). What Do Pre-Service Elementary Teachers Perceive as Positive and Negative Experiences in Physical Education? Physical and Health Education Journal, 64, 26-29.

Tong, X. (2013). The Effect of Mobile Phone Network on College Students' Interpersonal Contact and Countermeasure Research. Master's Dissertation, Dalian: Dalian University of Technology.

Wang, W. (2012). Inter-Personal Problems in Mobile-Addiction College Students: An Exploration Based on Emotion Expression and Emotion Recognition. Master's Dissertation, Jinhua: Zhejiang Normal University.

Wang, Y. (2014). The Research on the Effect of Mobile on College Students' Interpersonal Contact. Master's Dissertation, Tianjin: Tianjin Normal University.

Winfield, L. F. (1991). Resilience, Schooling, and Development in African-American Youth: A Conceptual Framework. Education and Urban Society, 24, 5-14.

https://doi.org/10.1177/0013124591024001001

Xia, L. (2013). The Current Situation and Influence of Contemporary University Students' Mobile Phone Use-Take Two Universities in Wuhan as Example. Master's Dissertation, Wuhan: Huazhong University of Science and Technology. 